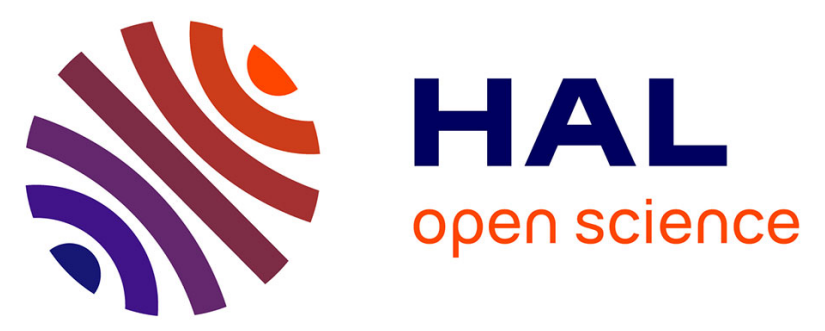

\title{
Predictive factors for non-participation or partial participation in breast, cervical and colorectal cancer screening programmes
}

Sébastien Dawidowicz, Julien Le Breton, Laura Moscova, Vincent Renard, Sandrine Bercier, Zahida Brixi, Etienne Audureau, Pascal Clerc, Sylvie Bastuji-Garin, Emilie Ferrat

\section{To cite this version:}

Sébastien Dawidowicz, Julien Le Breton, Laura Moscova, Vincent Renard, Sandrine Bercier, et al.. Predictive factors for non-participation or partial participation in breast, cervical and colorectal cancer screening programmes. Family Practice, 2020, 37 (1), pp.15-24. 10.1093/fampra/cmz031. hal03244263

\section{HAL Id: hal-03244263 \\ https://hal.science/hal-03244263}

Submitted on 1 Jun 2021

HAL is a multi-disciplinary open access archive for the deposit and dissemination of scientific research documents, whether they are published or not. The documents may come from teaching and research institutions in France or abroad, or from public or private research centers.
L'archive ouverte pluridisciplinaire HAL, est destinée au dépôt et à la diffusion de documents scientifiques de niveau recherche, publiés ou non, émanant des établissements d'enseignement et de recherche français ou étrangers, des laboratoires publics ou privés. 


\section{Predictive factors for non-participation or partial participation in breast, cervical and colorectal cancer screening programmes.}

Article category : Epidemiology

Running title: cancer screening participation rates in women

Keywords: Cancer Care / Oncology ; Cancer, Breast ; Cancer, Cervical ; Cancer, Colorectal ; Primary Care ; Screening

Sébastien Dawidowicz ${ }^{1,2}$; Julien Le Breton ${ }^{1,3}$; Laura Moscova ${ }^{1}$; Vincent Renard ${ }^{1,3}$; Sandrine Bercier $^{1,4}$; Zahida Brixi ${ }^{4}$; Etienne Audureau ${ }^{3,5}$; Pascal Clerc ${ }^{3,6}$; Sylvie Bastuji-Garin ${ }^{3,5}$; Emilie Ferrat $^{1,3}$

${ }^{1}$ Université Paris-Est Créteil (UPEC), School of Medicine, Primary Care Department, Créteil, F-94010 France.

${ }^{2}$ Maison de Santé Pluri-professionnelle de Sucy-en-Brie, F-94370, Sucy-en-Brie, France.

${ }^{3}$ Université Paris-Est Créteil (UPEC), DHU A-TVB, IMRB, EA 7376 CEpiA (Clinical Epidemiology And Ageing Unit), Créteil, F-94000, France.

${ }^{4}$ Association de Dépistage Organisé des Cancers dans le Val-de-Marne, ADOC 94, Joinvillele-Pont, F-94340, France.

${ }^{5}$ Assistance Publique Hôpitaux de Paris (APHP), Henri Mondor Hospital, Department of Public Health, Créteil, F-94000, France.

${ }^{6}$ Université de Versailles, School of Medicine, Primary Care Department, Versailles, F-78000 France.

This work has been presented in part at the CNGE congress (November 2016, Grenoble, France).

\section{CORRESPONDING AUTHOR:}

Dr E. Ferrat 
Université Paris-Est Créteil (UPEC), School of Medicine, Primary Care Department, Créteil, F-94010 France.

Tel.: +33-149-813-721; Fax: +33-149-814-481, emilie.ferrat@u-pec.fr

Keywords: cancer, screening, primary care, public health

Word count: 2901 (max: 3000)

\title{
KEY MESSAGES
}

- Only $11.5 \%$ of women participate in all three cancers screening

- Social deprivation is predictive of the 3 cancers screening non-participation

- More deprivation level affect more non-participation in cancer screening

\begin{abstract}
BACKGROUND : No study has investigated factors associated with non-participation or partial participation in the different combination patterns of screening programmes for all three cancers i.e., breast, colorectal and cervical cancer.

METHODS : In a retrospective cohort study, we sought to describe combinations of cancer screening participation rates among women in the Val-de-Marne area of France, and to identify individual and contextual factors associated with non-participation or partial participation.
\end{abstract}

RESULTS : Women aged between 50 and 65 and who were eligible for all three screening programmes $(n=102,219)$ were analyzed in multilevel logistic models, with the individual as the level 1 variable and the place of residence as the level 2 variable. The women who did not participate in any of the screening programmes were $34.4 \%$, whereas $30.1 \%, 24 \%$, and $11.5 \%$ participated in one, two or all three screening programmes, respectively. Age below 55, a previous false-positive mammography, prior opportunistic mammography only, no previous 
mammography, membership of certain health insurance schemes (all $\mathrm{p}<0.05$ ), and residence in a deprived area $(\mathrm{p}<0.001)$ were independently associated with non-participation or partial participation. We observed a stronger effect of deprivation on non-participation in all three cancers than in combinations of screening programmes.

CONCLUSION : Our findings suggest that the health authorities should focus on improving cancer screenings in general, rather than screenings for specific types of cancer, especially among younger women and those living in the most socially deprived areas. 


\section{INTRODUCTION}

Breast cancer and colorectal cancer (CRC) are the most incident cancers among women, and respectively account for first and third leading causes of cancer death ${ }^{1}$. Cervical cancer is ranked fourth in terms of incidence and cancer-related deaths among women worldwide ${ }^{1}$. Screening programmes for these cancers among women (mammography, faecal occult blood testing (FOBT) and Pap testing) have been extensively studied ${ }^{2-4}$. The latest European guidelines recommend that participation rates of at least $70 \%, 50 \%$ and $80 \%$ are needed to obtain significant decreases in mortality rates for breast cancer, cervical cancer and CRC, respectively ${ }^{5-7}$. The French health authorities launched nationwide, free-of-charge, organized screening (OS) programmes for breast cancer in 2004 and for CRC in 2009. Around $10 \%$ of French women undergo opportunistic screening (OpS), i.e. individually prescribed mammography ${ }^{8}$. Although French cervical cancer screening was opportunistic until 2018, a pilot OS programme (restricted to non-up-to-date women) was launched in 13 French counties in 2010. From 2010 to 2012, nationwide participation rates in these programmes for women were lower than expected (52\% (only OS), 34\%, and $62 \%$ for breast cancer, CRC, and cervical cancer, respectively) $^{9-11}$.

The French screening programmes for these cancers target women between the ages of 50 and 65. Low individual socioeconomic status, residence in a deprived area, poor access to healthcare, smoking, disability, and previous non-participation in cancer screening programmes were associated with non-participation in breast cancer, CRC, and cervical cancer screening, and assessed in isolation from one another ${ }^{12-17}$. Other factors linked to nonparticipation included very old age for breast cancer screening, younger age for CRC screening, and older age for cervical cancer screening ${ }^{18,19}$. Factors associated with nonparticipation in combinations of screening programmes have only been studied for breast and cervical cancers; the significant factors were older age, poor socioeconomic status, active smoking, and residence in a rural area ${ }^{20}$. However, to date no study has investigated factors associated with non-participation or partial participation in the different combination patterns 
of screening programmes for all three cancers (i.e. participation in a single programme, two programmes, or all three programmes).

The primary objective of the present study was to describe patterns and rates of nonparticipation or partial participation in combinations of screening programmes for all three cancers by French women aged 50 to 65 years. The secondary objective was to investigate individual and contextual factors associated with non-participation or partial participation. We hypothesized that age, poor access to healthcare, and social deprivation were associated with low screening rates, and that a gradient would be observed across the combinations (e.g. social deprivation would be more strongly linked to non-participation than to participation in one, two or three screening programmes).

\section{MATERIALS AND METHODS}

\section{Setting}

This retrospective cohort study was conducted in the Val-de-Marne county - part of the greater Paris urban area with a population of 1.3 million (accounting for $2 \%$ of the French population). This area launched screening campaigns for breast cancer in 2004, for CRC in 2007, and for cervical cancer in 2010.

\section{Cancer screening programmes for women}

The Val-de-Marne cancer screening centre (Association de dépistage organisé des cancers dans le Val-de-Marne (ADOC94)) sent a letter offering free-of-charge mammographic screening to all female residents aged between 50 and 74. Women who had not replied 6 months later were sent a reminder. The data on breast cancer screening (including previous screening visits) were based on the women's replies (for OpS) and/or the case report form for participation in OS programmes. Likewise, all women aged 50-74 were invited to participate in CRC screening and to collect a free FOBT kit from their GP. Women who had not replied 6 months later were sent a reminder letter. Up until 2015, women who had not replied to the first reminder were sent a second letter and an FOBT kit. For cervical cancer screening, 
women aged 25-65 and who had not undergone a documented Pap test in the previous three years were invited by post to arrange a screening visit with their GP, gynaecologist, midwife or local medical laboratory. Women who had not replied 12 months later were sent a reminder.

\section{Data sources}

Data on individual predictors were directly extracted in January 2016 from the ADOC94 database such as the women's individual factors, participation in screening programmes, and GPs information. Those informations were collected from women, radiologist centres, physicians and for Pap test status, from the national health insurance database. The study database was registered with the French National Data Protection Commission (CNIL; reference: 187584). Data on contextual predictors (i.e. area of residence characteristics) were obtained from the French National Institute of Statistics and Economic Studies (INSEE) database.

\section{Study population}

The main inclusion criteria were (i) age between 50 and 65, (ii) eligibility for all three screening programmes, (iii) residence in the study area, and (iv) invitation for breast cancer and CRC screenings between November 2010 and October 2012. To avoid major selection bias, we did not include all women invited to attend a cervical cancer OS programme in the Val de Marne area, since only women lacking up-to-date Pap testing would have been included ( $n=68,936,67.4 \%$ of the eligible population) (Figure 1).

\section{Outcomes}

Participation was quantified as the combined OS $+\mathrm{OpS}$ rate. The primary outcome (levels of participation in one to three screening programmes) was classified into four modalities: nonparticipation (coded as "NP"), participation in one of the three programmes ("P1"), participation in two of the three programmes ("P2"), and full participation ("FP"). Participation in breast cancer and CRC screening programmes was defined as participation 
within 2 years of receipt of the initial invitation sent during November 2010 and October 2012. Participation in the cervical cancer screening programme was defined as participation within 3 years of having been invited to attend one of the other screening programmes.

\section{Potential predictors}

The putative individual predictors of non-participation or partial participation (studied at level 1) included age at the time of the first invitation (for breast cancer and CRC screening) and membership of various special statutory health insurance schemes (e.g. schemes for employees, farmers and agricultural workers, self-employed people, civil servants, etc.). We created a four-category variable for mammography: no previous mammography (in either OS or OpS programmes); mammography in an OpS programme; a normal mammography in an OS programme; and a false-positive mammography finding in an OS programme (including non-malignant breast tumors) (Table 3). We also extracted the following predictors: previous screening for $\mathrm{CRC}$ and cervical cancer; screening rank (the number of visits to breast cancer and CRC screening programmes, including the current programme; this information was not available for cervical cancer screening); receipt of a first reminder for CRC and breast cancer screening (after 6 months) or for cervical cancer screening (after 12 months); and receipt of a second reminder and an FOBT kit.

Area of residence (according to the latest French census data) was studied at level 2. In relation to this level, the following contextual factors were analyzed: socioeconomic status (quintiles of the European Deprivation Index (Pornet et al, 2013)), and healthcare access by the median number of GP's per 100,000 people (in tertiles), and the local presence of a gynaecologist, gastroenterologist, radiologist, midwife and/or health centre ${ }^{21}$.

\section{Statistical analysis}

We assessed the distributions of the different combinations of NP, P1 and P2 (with FP as the reference category), and applied random-intercept multilevel logistic models with individuals (level 1) nested into areas (level 2). Univariable analyses were performed with the chi-square test for categorical variables and the Kruskal-Wallis test for continuous variables. Variables 
with $p<0.2$ were selected for multivariable analysis. Confounders and interactions were tested in bivariate models. To avoid introducing highly correlated variables into the models (e.g. previous mammography in an OS programme and screening rank for breast cancer OS; previous FOBT, previous mammography, and previous Pap test), only the most relevant variables (according to the Bayesian information criterion) were included in the multivariable models. We first used an empty multilevel logistic model to estimate whether significant clustering (assessed with the intra-class correlation coefficient (ICC)) occurred within areas of residence for $\mathrm{NP}$ or $\mathrm{P} 1$ or $\mathrm{P} 2{ }^{22}$. Next, we included the level 1 and level 2 predictors, and assessed the extent to which area patterns affected the probability of patient participation. We computed the ICCs and thus estimated the proportion of total variance in the participation rate that was attributable to inter-areas. We also estimated the proportion of between-group variability related to the contextual factors at the group level, after the inclusion of level 1 and level 2 variables ${ }^{23}$.

All tests were two-sided, and the threshold for statistical significance was $p \leq 0.05$. Subgroup comparisons were corrected for multiple comparisons using Bonferroni's method. (threshold: $p<0.008)$. All statistical analyses were performed with Stata software (StataCorp, College Station, TX, USA).

\section{RESULTS}

\section{Study population}

A total of the 102,219 women were analysed (Table 1). The median [interquartile range (IQR)] age at the time of the first screening invitation (breast cancer or CRC) was 55.7 [51.959.7]. The screening rates for breast cancer, CRC and cervical cancer were respectively $44.6 \%$ (including 3.6\% in OpS programmes), 24.7\% (all in OS) and 43.3\% (Table 2). The NP group comprised 35,159 women $(34.4 \%)$, with 30,800 women $(30.1 \%$ ) in P1, 24,510 women $(24.0 \%)$ in $\mathrm{P} 2$ and 11,750 women $(11.5 \%)$ in FP. 


\section{Factors associated with non-participation/partial participation}

Significant individual and contextual predictors, associated with non-participation or partial participation are mention in table 3 .

Given the strong correlation between non-participation and previous mammography status (Table 4), the latter was not included in the multivariable model of non-participation. The multilevel multivariable analysis evidenced significant variability from one area of residence to another $(\mathrm{p}<0.001)$. The following factors were associated with non-participation: younger age, self-employment, agricultural occupation, membership of special health insurance schemes in large companies, and residence in deprived areas. The same factors were associated with partial participation as well as a history of false-positive mammography findings in OS programmes, mammography in OpS programmes only, and no previous mammography.

The non-participation and partial participation rates varied significantly from one area of residence to another (from $2.1 \%$ to $0.4 \%$, in the empty models). After adjustment, $1 \%, 0.6 \%$ and $0.3 \%$ of the total variability were explained by inter-area differences in NP, P1 and P2, respectively (Table 4). Socioeconomic status (the European Deprivation Index) accounted for $47 \%, 39.9 \%$ and $12.5 \%$ of the inter-area variability in NP, P1 and P2, respectively. Lastly, we observed a gradient in ORs for the most deprived area and self-employment for the NP, P1 and P2 groups; these factors had a stronger negative effect for NP than they did for P1 and P2.

\section{Subgroup analyses}

Compared with the FP group, the absence of previous mammography was strongly associated with P1 women who did not participate in CRC or breast cancer screening but had participated in cervical cancer screening (online supplement Table S1). Older age, residence in deprived areas, and the absence of mammography in OpS programmes were associated with P2 women who did not participate in cervical cancer screening but had participated in both breast and CRC screening programmes, relative to other combinations (online supplement Table S2). 


\section{DISCUSSION}

We found that only $11.5 \%$ of the study population participated in all three screening programmes. Overall, $24 \%$ of the women participated in two programmes (13.7\% for breast cancer + cervical cancer, $6.3 \%$ for $\mathrm{CRC}+$ breast cancer, and $4 \%$ for cervical cancer $+\mathrm{CRC}$ ), and $30.1 \%$ participated in one programme $(13.1 \%$ for breast cancer, $14.1 \%$ for cervical cancer, and $2.9 \%$ for CRC). The non-participation rate was $34.4 \%$. When compared with participation in all three screening programmes, the factors linked to non-participation or partial participation were young age, membership of certain health insurance schemes, a previous false-positive mammography in an OS programme, previous mammography in an OpS programme only, no previous mammogram (in OS or OpS programmes), and residence in the most deprived areas. Social deprivation was strongly associated with non-participation in general and non-participation in cervical cancer screening.

\section{Strengths and limitations}

The present study is the first to have investigated individual and contextual factors associated with non-participation or partial participation in breast cancer, cervical cancer and CRC screening among women aged 50-65. We focused on screening rates in general (rather than participation in OS programmes only) because they better reflect attitudes toward prevention. Furthermore, we used multilevel models because they are more appropriate for hierarchical data. However, data on breast cancer OpS programmes depends on women replying to the invitation, and so we may have underestimated this frequency. A substantial proportion of women classified as non-participants may have been screened in OpS programmes. The use of aggregate data for deprivation avoids declarative bias in survey studies but prevents one from drawing conclusions about individuals. Lastly, health professional density is not the best way to measure access to healthcare because it does not reflect geographical accessibility ${ }^{24}$. 


\section{Comparison with previous literature}

Our OS rates for breast cancer $(44.6 \%)$ and CRC (24.7\%) were similar those reported for women aged 50-74 in the Val-de-Marne district in 2011-2012 (43.4\% and 29.2\%) respectively) ${ }^{9,10}$. However, the breast cancer OpS rate $(3.6 \%)$ was lower than the French national value $(10 \%)^{8,25}$. This difference might due to the low response rate to postal invitations in the breast cancer OS programme. The cervical cancer screening rate $(\mathrm{OS}+\mathrm{OpS})$ of $43.3 \%$ was participants attended all three cancer screening programme. We did not find any comparative literature data on FP rates. In line with the literature, the lowest participation rate was observed for CRC screening ${ }^{10}$.

As in other studies, age $<55$ was associated with non-participation in breast cancer and CRC screening ${ }^{26,28,29}$. Older age has been linked with non-participation in cervical cancer screening ${ }^{26,27}$. Self-employed status was previously found to be associated with nonparticipation in breast cancer screening ${ }^{19}$. These women's professional constraints may limit their availability for screening ${ }^{30}$. As reported previously, residence in the most deprived areas was associated with non-participation or only partial participation in the three cancer screening programmes ${ }^{12,14}$. The association effect was stronger for non-participation and participate in cervical cancer screening only.

We found a previous false-positive mammography findings were associated with nonparticipation or partial participation - particularly for cervical cancer screening. Other studies have reported that these mammography findings decrease subsequent participation in mammography screening ${ }^{31,32}$. Previous mammography in an OpS programme only was strongly associated with non-participation or partial participation - especially for participation in cervical cancer screening but not in CRC and breast cancer screening. We hypothesize that many of these women are being followed up by gynaecologists. Gynaecological follow-up in France is reported to be associated with higher participation in cervical cancer screening and breast cancer OpS than in breast cancer OS ${ }^{20}$. Moreover, gynaecologists may not systematically promote participation in OS for both CRC and breast cancer. 
The absence of a previous mammography was associated with non-participation in all three screening programmes, in the breast cancer and CRC screening programme. Some studies have highlighted an association between previous mammography and subsequent mammography, Pap testing ${ }^{14}$ and FOBT use ${ }^{20}$. This might also reflect a "mass screening" effect: a woman participating in one OS programme is more likely to participate in other OS programmes.

Lastly, many women (particularly the most economically deprived) do not have an sufficiently prevention-focused attitude to cancer screening - probably because of other priorities ${ }^{33,34}$ and/or a lower educational level ${ }^{20}$. We suggest that some following interventions might improve full participation in cancer screening programmes. First, media campaigns and public health programmes for women should focus on cancer screening in general, and should adjust the level and type of information to suit the target population's socioeconomic level ${ }^{35}$. This corresponds to proportionate universalism, in which the intensity is proportional to the degree of need ${ }^{36}$.

Then, a national cervical cancer screening campaign (launched in France in 2018) might improve screening rates for both cervical cancer and other cancers ${ }^{37,38}$. And, for breast cancer, physicians should encourage women to participate in OS programmes rather than OpS programmes. Physicians should also suggest CRC screening when they inform women about screening programmes for gynaecological cancer ${ }^{39}$. Moreover, GPs have a central role in the general approach to prevention ${ }^{36}$. Initial and continuing medical education should focus on a broad-based approach to cancer screening (rather screening for just one type of cancer) and should include the concept of patient-centred care. As key stakeholders in public health, GPs maybe able to remove certain individual barriers and thus increase screening rates ${ }^{40-43}$.

\section{Conclusions}

A small proportion of women (11.5\%) participated in all three screening programmes (i.e. breast cancer, CRC and cervical cancer screening). Age $<55$, a previous false-positive 
mammography, previous mammography in OpS programmes only, no previous mammography, residence in a deprived area, and membership of certain health insurance schemes were predictive of non-participation or partial participation in combination of screening programmes for all three cancers. We observed a stronger effect of deprivation on non-participation than on participation in combinations of screening programmes. Our findings highlight the need to target women aged 50 to 65 years and promote better overall participation in cancer screening programmes - especially among younger women and those living in highly deprived areas. Gynaecologists and GPs have a central role in informing women about screening programmes and improving screening rates.

\section{CONFLICT OF INTEREST}

None

\section{FUNDING}

This research did not receive any specific grant from funding agencies in the public, commercial, or not-for-profit sectors.

\section{ACKNOWLEDGEMENTS}

We thank Frederic Grezis (Epiconcept, Paris, France) for assistance with data management and David Fraser and Laura Smales, for revising the manuscript.

We thank Ludivine Launais and Carole Pornet for the transmission of EDI through the national methodological platform for the Study and Reduction of Social Inequalities in Oncology (ERISC platform, INSERM Unit lU1086 "Cancers \& Prevention"). 


\section{REFERENCES}

1. Torre LA, Bray F, Siegel RL, Ferlay J, Lortet-Tieulent J, Jemal A. Global cancer statistics, 2012. CA Cancer J Clin. 2015;65(2):87-108. doi:10.3322/caac.21262

2. Hewitson P, Glasziou P, Watson E, Towler B, Irwig L. Cochrane systematic review of colorectal cancer screening using the fecal occult blood test (hemoccult): an update. Am J Gastroenterol. 2008;103(6):1541-1549. doi:10.1111/j.1572-0241.2008.01875.x

3. Peirson L, Fitzpatrick-Lewis D, Ciliska D, Warren R. Screening for cervical cancer: a systematic review and meta-analysis. Syst Rev. 2013;2:35. doi:10.1186/2046-4053-2-35

4. Nelson HD, Fu R, Cantor A, Pappas M, Daeges M, Humphrey L. Effectiveness of Breast Cancer Screening: Systematic Review and Meta-analysis to Update the 2009 U.S. Preventive Services Task Force Recommendation. Ann Intern Med. 2016;164(4):244255. doi:10.7326/M15-0969

5. Arbyn M, Anttila A, Jordan J, et al. European guidelines for quality assurance in cervical cancer screening. Ann Oncol. 2010;21(3):448-458.

6. von Karsa L, Patnick J, Segnan N, et al. European guidelines for quality assurance in colorectal cancer screening and diagnosis: Overview and introduction to the full Supplement publication. Endoscopy. 2013;45(1):51-59. doi:10.1055/s-0032-1325997

7. Dimitrova N, Saz Parkinson Z, Bramsfeld A., Uluturk Tekin A., Bocchi G, Lerda D. European Guidelines for Breast Cancer Screening and Diagnosis. EU Sci Hub. 2016. doi:doi: $10.2788 / 503032$

8. Ouédraogo S, Dabakuyo-Yonli TS, Roussot A, et al. Dépistage du cancer du sein dans treize départements français. Bull Cancer (Paris). 2015;102(2):126-138.

9. INVS (Institut de Veille Sanitaire). Taux de participation au programme de dépistage organisé du cancer du sein 2011-2012. 2013. http://invs.santepubliquefrance.fr/Dossiersthematiques/Maladies-chroniques-et-traumatismes/Cancers/Evaluation-des-programmesde-depistage-des-cancers/Evaluation-du-programme-de-depistage-du-cancer-dusein/Indicateurs-d-evaluation/Taux-de-participation-au-programme-de-depistageorganise-du-cancer-du-sein-2011-2012.

10. INVS (Institut de Veille Sanitaire). Taux de participation au programme de dépistage

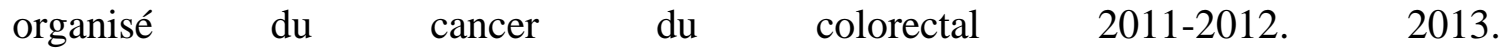
http://invs.santepubliquefrance.fr/Dossiers-thematiques/Maladies-chroniques-ettraumatismes/Cancers/Evaluation-des-programmes-de-depistage-descancers/Evaluation-du-programme-de-depistage-du-cancer-colorectal/Indicateurs-devaluation/Taux-de-participation-au-programme-de-depistage-organise-du-cancercolorectal-2011-2012.

11. Duport N, Salines E, Grémy I. Premiers résultats de l'évaluation du programme expérimental de dépistage organisé du cancer du col de l'utérus, France, 2010-2012. Bull Epidémiol Hebd. 2014;20:228-34.

12. Pornet C. Influence de l'environnement socioéconomique et de l'offre de soins sur la participation aux dépistages organisés des cancers du sein et du colon-rectum à l'aide d'un nouvel outil: the european deprivation index. 2013. http://www.theses.fr/2013CAEN3167. Accessed May 20, 2017. 
13. Weber MF, Cunich M, Smith DP, Salkeld G, Sitas F, O’Connell D. Sociodemographic and health-related predictors of self-reported mammogram, faecal occult blood test and prostate specific antigen test use in a large Australian study. BMC Public Health. 2013;13:429. doi:10.1186/1471-2458-13-429

14. Delpierre C, Fantin R, Chehoud H, Nicoules V, Bayle A, Souche A. Inégalités sociales d'accès aux soins et à la prévention en Midi-Pyrénées, France, 2012. Bull Epidémiol Hebd. 2016;(1):2-8.

15. Barry J. The Relationship Between the Supply of Primary Care Physicians and Measures of Breast Health Service Use. J Womens Health. 2017;26(5):511-519. doi:10.1089/jwh.2016.5830

16. Akinyemiju TF, McDonald JA, Lantz PM. Health care access dimensions and cervical cancer screening in South Africa: analysis of the world health survey. BMC Public Health. 2015;15. doi:10.1186/s12889-015-1686-5

17. Davis MM, Renfro S, Pham R, et al. Geographic and population-level disparities in colorectal cancer testing: A multilevel analysis of Medicaid and commercial claims data. Prev Med. 2017;101:44-52. doi:10.1016/j.ypmed.2017.05.001

18. Pornet C, Dejardin O, Morlais F, Bouvier V, Launoy G. Socioeconomic determinants for compliance to colorectal cancer screening. A multilevel analysis. J Epidemiol Community Health. 2010;64(4):318-324.

19. Pornet $\mathrm{C}$, Dejardin O, Guittet L, Quertier MC, Bouvier V, Launoy G. Influence de l'environnement Socio-Économique et de l'offre de Soins Sur La Participation Au Programme de Dépistage Organisé Du Cancer Du Sein. BEH; 2012.

20. Duport N, Serra D, Goulard H, Bloch J. Quels facteurs influencent la pratique du dépistage des cancers féminins en France? Rev DÉpidémiologie Santé Publique. 2008;56(5):303-313.

21. Ferrat E, Le Breton J, Veerabudun K, et al. Colorectal cancer screening: factors associated with colonoscopy after a positive faecal occult blood test. $\mathrm{Br} J$ Cancer. 2013;109(6):1437.

22. Snijders T. Multilevel Analysis: An Introduction to Basic and Advanced Multilevel Modeling. $\quad 1999$. https://books.google.fr/books?hl=fr\&lr=\&id=G8fhqL9xHOAC\&oi=fnd\&pg=PR9\&dq= Multilevel+analysis:+An+introduction+to+basic+and+advanced+multilevel+modeling.+ \&ots=LwoAXZqkBW\&sig=HhmnQKHXvQF_5_eNYO2SV6KfHVE. Accessed May $20,2017$.

23. Merlo J, Chaix B, Ohlsson H, et al. A brief conceptual tutorial of multilevel analysis in social epidemiology: using measures of clustering in multilevel logistic regression to investigate contextual phenomena. J Epidemiol Community Health. 2006;60(4):290-297. doi:10.1136/jech.2004.029454

24. Guagliardo MF. Spatial accessibility of primary care: concepts, methods and challenges. Int J Health Geogr. 2004;3(1):3. doi:10.1186/1476-072X-3-3 
25. Haute Autorite de Santé. La Participation au Dépistage du Cancer du sein chez les Femmes de 50 à 74 ans en France: Situation Actuelle et Perspectives d'évolution. Breast Cancer Screen Uptake Women Aged. 2011:50-74.

26. Sicsic J, Franc C. Obstacles to the uptake of breast, cervical, and colorectal cancer screenings: what remains to be achieved by French national programmes? BMC Health Serv Res. 2014;14:465. doi:10.1186/1472-6963-14-465

27. Chauvin P, Parizot I. Vulnérabilités sociales, santé et recours aux soins dans les quartiers défavorisés franciliens: résultats d'enquêtes statistiques conduites dans des quartiers de la politique de la ville (rapport). Paris Délégation Interministérielle À Ville. 2007.

28. Pivot X, Rixe O, Morere J, et al. Breast cancer screening in France: results of the EDIFICE survey. Int J Med Sci. 2008;5(3):106-112.

29. Fon Sing M, Leuraud K, Duport N. Characteristics of French people using organised colorectal cancer screening. Analysis of the 2010 French Health, Healthcare and Insurance Survey. Prev Med. 2013;57(1):65-68. doi:10.1016/j.ypmed.2013.03.008

30. Sauze L, Ha-Vinh P, Régnard P. Affections de longue durée et différences de morbidité entre travailleurs salariés et travailleurs indépendants, Summary. Prat Organ Soins. 2011;42(1):1-9.

31. Seigneurin A, Exbrayat C, Labarère J, Delafosse P, Poncet F, Colonna M. Association of diagnostic work-up with subsequent attendance in a breast cancer screening program for false-positive cases. Breast Cancer Res Treat. 2011;127(1):221-228. doi:10.1007/s10549-010-1118-2

32. Salz T, DeFrank JT, Brewer NT. False positive mammograms in Europe: do they affect reattendance? Breast Cancer Res Treat. 2011;127(1):229-231. doi:10.1007/s10549-010$1245-9$

33. Barreau B, Hubert A, Dilhuydy M-H, Seradour B, Dilhuydy J-M. Qualitative study of motivational and biocultural factors for participation in breast cancer screening. PsychoOncol. 2008;2(1):13-20.

34. Ferrat E, Le Breton J, Djassibel M, et al. Understanding barriers to organized breast cancer screening in France: women's perceptions, attitudes, and knowledge. Fam Pract. 2013;30(4):445-451. doi:10.1093/fampra/cmt004

35. Cambon L, Mangin G, Barthélémy L. Expérimentation d'une démarche participative sur le dépistage des cancers auprès de femmes en situation de précarité. Santé Publique. 2007;19(6):513-523.

36. Marmot MG, Allen J, Goldblatt P, et al. Fair society, healthy lives: Strategic review of health inequalities in England post-2010. 2010. http://discovery.ucl.ac.uk/111743/. Accessed May 20, 2017.

37. Canfell K, Sitas F, Beral V. Cervical cancer in Australia and the United Kingdom: comparison of screening policy and uptake, and cancer incidence and mortality. Med $J$ Aust. 2006;185(9):482-486.

38. Ministère des Affaires Sociales et de la Santé. Plan Cancer 2014-2019. 2014. http://www.e-cancer.fr/Expertises-et-publications/Catalogue-des-publications/PlanCancer-2014-2019. Accessed May 20, 2017. 
39. Carlos RC, Fendrick AM, Ellis J, Bernstein SJ. Can breast and cervical cancer screening visits be used to enhance colorectal cancer screening? J Am Coll Radiol JACR. 2004;1(10):769-776. doi:10.1016/j.jacr.2004.05.018

40. Le Breton J, Journy N, Attali C, et al. Improving participation in colorectal cancer screening: targets for action. Prev Med. 2012;55(5):488-492. doi:10.1016/j.ypmed.2012.08.004

41. Aubin-Auger I, Laouénan C, Le Bel J, et al. Efficacy of communication skills training on colorectal cancer screening by GPs: a cluster randomised controlled trial. Eur $J$ Cancer Care (Engl). 2016;25(1):18-26. doi:10.1111/ecc.12310

42. Pornet C, Denis B, Perrin P, Gendre I, Launoy G. Predictors of adherence to repeat fecal occult blood test in a population-based colorectal cancer screening program. $\mathrm{Br} J$ Cancer. 2014;111(11):2152-2155. doi:10.1038/bjc.2014.507

43. Damery S, Clifford S, Wilson S. Colorectal cancer screening using the faecal occult blood test (FOBt): a survey of GP attitudes and practices in the UK. BMC Fam Pract. 2010;11:20. doi:10.1186/1471-2296-11-20 
Individual characteristics ( $\mathrm{n}=102,219)$

Age at the time of the initial invitation for breast or colorectal cancer screening (years): median [IQR]

$55.7[51.9-59.7]$

Age group (years)

50-54

$46,765(45.8 \%)$

$55-59$

$31,105(30.4 \%)$

60-64

$24,349(23.8 \%)$

Statutory healthcare insurance scheme

Salaried workers

$78,831(77.1 \%)$

Civil servants

$13,812(13.5 \%)$

$463(0.5 \%)$

Agricultural occupations

$4,127(4.0 \%)$

$4,986(4.9 \%)$

Large public-sector companies with special schemes

$44,141(43.2 \%)$

$3,861(8.7 \%)$

$4,428(4.3 \%)$

Previous mammography in OpS programmes only

$24,231(23.7 \%)$

Rank 1

$15,578(15.2 \%)$

Rank 2

$11,214(11.0 \%)$

Rank 3

$9,221(9.0 \%)$

Rank 4

$3,988(3.9 \%)$

Rank $\geq 5$

$37,987(37.2 \%)$

Missing data

$65,452(64.0 \%)$

Postal reminder sent 6 months after the initial invitation

$24,582(24.0 \%)$

At least 1 previous FOBT

$4,582(24.0 \%)$

Screening rank ${ }^{a}$

Rank 1

$19,178(18.8 \%)$

Rank 2

15,332 (15.0\%)

Rank $\geq 3$

2,954 (2.9\%)

Missing data

64,755 (63.3\%)

85,734 (83.9\%)

77,041 (75.4\%)

A second reminder with a FOBT kit sent to the home 6 months after the first reminder

\section{Cervical cancer}

Pap test in the previous 3 years

$28,187(27.6 \%)$

$68,936(67.4 \%)$

Invitation letter for the current screening programme

$24,352(35.3 \%)$

Postal reminder sent 12 months after the initial invitation, $n=68,936^{b}$

\section{Contextual characteristics}

Socio-economic deprivation in the area of residence

European Deprivation Index

Quintile 1 (least deprived)

Quintile 2

$21,164(20.7 \%)$

Quintile 3

20,372 (19.9\%)

Quintile 4

$19,947(19.5 \%)$

Quintile 5 (most deprived) 
General practitioner density per 100,000 of the population ${ }^{f}$

Tertile 1 (lowest density)

$29,288(30 \%)$

Tertile 2

Tertile 3 (highest density)

Presence of specialist physicians and healthcare professionals in the area

Gynaecologist

Gastroenterologist

Radiologist

Midwife

Medical centre

Categorical variables are quoted as the $\mathrm{n}(\%)$, and continuous variables are quoted as the median [interquartile range (IQR)) or in quintiles. OS: organized screening; FOBT: faecal occult blood test.

Data extraction in January 2016. Invitation sent during November 2010 and October 2012.

a. The rank is defined as a woman's total number of screening visits (including the current programme) for each type of cancer; these data were not available for cervical cancer screening programmes.

b. Number of women invited to the current OS programme in the study period

c. Number of areas with available information $=525$

d. Number of areas with available information $=505$

e. The European Deprivation Index is based on 11 census variables, expressed as percentages (Non-home-owners, unemployed people, foreign nationals, non-car-owners, unskilled workers/farmers, households of more than 6 people, low educational level, and single-parent households). The EDI ranged from -12.3 to +23.6 , and was categorised in quintiles (with quintile 1 representing the least deprived area and quintile 5 representing the most deprived areas).

f. General practitioner (GP) density was categorised in tertiles. Tertile 0: 0 GPs; tertile 1: 1-2 GPs; tertile 3: 3-16 GPs. 
Table 2: Screening rates for breast, colorectal and cervical cancer, for each of the eight possible combinations

\begin{tabular}{ccccc} 
& & Type of cancer screening & N= 102,219 \\
\hline Breast & Colorectal & Cervical & Coverage \% (N) & Total \% (N) \\
\hline+ & + & + & $11.5 \%(11,750)$ & Full participation: 11.5\% (11,750) \\
+ & + & - & $6.3 \%(6,412)$ & Participation in 2 of the 3 screening \\
+ & - & + & $13.7 \%(14,002)$ & programmes: $24.0 \%(24,510)$ \\
\hline+ & + & + & $4.0 \%(4,096)$ & Participation in 1 of the 3 screening \\
- & - & - & $13.1 \%(13,400)$ & programmes: 30.1\% (30,800) \\
\hline- & + & - & $2.9 \%(2,979)$ & Non-participation: 34.4\% (35,159)
\end{tabular}

Data extraction in January 2016. Invitation sent during November 2010 and October 2012. 
Non-participation

(NP)

Participation in 1
screening
programme (P1)
$N=30,800(30.1 \%)$

creening programmes

(P2)

$\mathrm{N}=35,159(34.4 \%)$

$\mathrm{N}=30,800(30.1 \%)$

$N=24,510(24.0 \%)$

Full participation

(FP)

Individual characteristics (level 1)

\section{Age at the time of the initial invitation for breast or CRC screening (years)}

Median [IQR]

$55.8[51.9-59.8]$

$55.3[51.9-59.3]$

Age group

50-54

55-59

60-64

Statutory healthcare insurance scheme

Salaried workers

Civil servants

Agricultural occupations

Self-employed workers

Large companies

\section{Breast cancer screening}

Previous mammography status

At least 1 previous normal mammography result in OS

At least 1 previous abnormal mammography (false-positive

findings) in OS

Previous mammography in OpS programmes only

No previous mammography (OS or OpS)

Screening rank $n=64,232^{\text {b }}$

$$
\begin{aligned}
& \text { Rank } 1 \\
& \text { Rank } 2 \\
& \text { Rank } 3 \\
& \text { Rank } 4 \\
& \text { Rank } \geq 5
\end{aligned}
$$

Postal reminder sent 6 months after the initial invitation

\section{Colorectal cancer screening}

Previous FOBT

$15.7(44.8 \%)$
$10,983(31.2 \%)$
$8,444(24.0 \%)$
$26,594(75.6 \%)$
$4,539(12.9 \%)$
$199(0.6 \%)$
$2,012(5.7 \%)$
$1,815(5.2 \%)$

$14,935(48.5 \%)$

$9,001(29.1 \%)$

6,864 (22.3\%)

23,666 (76.8\%)

4,194 (13.6\%)

$164(0.5 \%)$

1,271 (4.1\%)

1,505 (4.9\%)

\begin{abstract}
$7,634(21.7 \%)$
843 (2.4\%)

537 (1.5\%)

26,145 (74.4\%)

6,405 (57.5\%)

2,772 (24.9\%)

1,252 (11.2\%)

497 (4.5\%)

215 (1.9\%)

32,952 (93.7\%)
\end{abstract}

11,876 (38.6\%)

2,207 (6.3\%)

$20,263(65.8 \%)$

$5,080(16.5 \%)$
55.8 [52.0-59.9]

11,129 (45.4\%)

$7,379(30.1 \%)$

$6,002(24.5 \%)$

19,162 (78.2\%)

3,445 (14.1\%)

75 (0.3\%)

$642(2.6 \%)$

$1,186(4.8 \%)$

13,139 (53.6\%)

$1,215(5.0 \%)$

1,772 (7.2\%)

8,384 (34.2\%)

6,998 (32.5\%)

5,095 (23.6\%)

4,117 (19.1\%)

3,746 (17.4\%)

$1,601(7.4 \%)$

$9,538(38.9 \%)$
$56.2[52.4-60.1]$

4,969 (42.3\%)

3,742 (31.9\%)

3,039 (25.9\%)

9,409 (80.1\%)

1,634 (13.9\%)

$25(0.2 \%)$

$202(1.7 \%)$

$480(4.1 \%)$

P value ${ }^{a}$

$N=11,750(11.5 \%)$ 
Rank 1
Rank 2
Rank $\geq 3$

Postal reminder sent 6 months after the initial invitation

A second reminder with a FOBT kit sent to the home 6 months after

the first reminder

\section{Cervical cancer screening}

Pap test in the previous 3 years

Invitation to OS

Postal reminder sent 12 months after the initial invitation $n=$

\section{$68,936^{\mathrm{C}}$}

\section{Contextual characteristics (level 2)}

\section{Level of area deprivation ${ }^{d}$}

European deprivation index $(n=102,197)^{d}$

$$
\begin{aligned}
& \text { Quintile } 1 \text { (least deprived) } \\
& \text { Quintile } 2 \\
& \text { Quintile } 3 \\
& \text { Quintile } 4 \\
& \text { Quintile } 5 \text { (most deprived) }
\end{aligned}
$$

\section{Healthcare in the area ${ }^{\mathrm{e}}$}

General practitioner density per 100,000 population $(n=97,711)^{e}$

Tertile 1 (lowest density)

Tertile 2

Tertile 3 (highest density)

Presence of specialist physicians and healthcare professionals in the area

$\begin{array}{lc}\text { Gynaecologist } & 4,600(13.6 \%) \\ \text { Gastroenterologist } & 2,820(8.3 \%) \\ \text { Radiologist } & 3,605(10.7 \%) \\ \text { Midwife } & 3,684(10.9 \%) \\ \text { Medical centre } & 3,234(9.6 \%)\end{array}$

$\begin{array}{ccccc}2,528(86.6 \%) & 5,845(70.7 \%) & 7,123(49.0 \%) & 3,682(31.3 \%) & <0.001 \\ 348(11.9 \%) & 2,130(25.8 \%) & 6,207(42.7 \%) & 6,647(56.6 \%) & \\ 42(1.5 \%) & 292(3.5 \%) & 1,199(8.5 \%) & 1,421(12.1 \%) & \\ 33,551(95.4 \%) & 28,022(91.1 \%) & 18,502(75.5 \%) & 5,659(48.2 \%) & <0.001 \\ 32,129(91.4 \%) & 26,477(86.0 \%) \%) & 15,389(62.8 \%) & 3,046(25.9 \%) & <0.001 \\ & & & & \\ 2,213(6.3 \%) & 9,150(29.2 \%) & 10,464(42.7 \%) & 6,360(54.1 \%) & <0.001 \\ 31,043(88.3 \%) & 20,077(65.2 \%) & 12,832(52.4 \%) & 4,984(42.4 \%) & <0.001 \\ 12,678(36.1 \%) & 6,932(22.5 \%) & 3,657(14.9 \%) & 1,087(9.3 \%) & <0.001\end{array}$

$\begin{array}{ll}6,352(18.1 \%) & 6,777(22.0 \%) \\ 6,907(19.7 \%) & 6,564(21.3 \%) \\ 6,895(19.6 \%) & 6,177(20.1 \%) \\ 7,379(21.0 \%) & 5,757(18.7 \%) \\ 7,615(21.7 \%) & 5,518(17.9 \%)\end{array}$

$5,516(22.5 \%)$

$2,800(22.2 \%)$

$<0.001$

$5,275(21.5 \%)$

$2,418(20.6 \%)$

$4,940(20.2 \%)$

$2,360(20.1 \%)$

$4,586(18.7 \%)$

$2,225(18.9 \%)$

$4,189(17.1 \%)$

$1,947(16.6 \%)$

$\begin{array}{lccc}10,256(30.3 \%) & 8,715(29.6 \%) & 6,969(29.9 \%) & 3,348(30.1 \%) \\ 12,538(37.1 \%) & 10,704(36.4 \%) & 8,532(36.6 \%) & 4,044(36.3 \%) \\ 11,029(32.6 \%) & 9,985(34.0 \%) & 7,823(33.5 \%) & 3,746(33.6 \%)\end{array}$

0.025

$\begin{array}{cccc}4,305(14.6 \%) & 3,385(14.5 \%) & 1,625(14.6 \%) & <0.001 \\ 2,671(9.1 \%) & 2,102(9.0 \%) & 1,006(9.0 \%) & 0.003 \\ 3,444(11.7 \%) & 2,712(11.6 \%) & 1,315(11.8 \%) & <0.001 \\ 3,444(11.7 \%) & 2,712(11.6 \%) & 1,279(11.5 \%) & 0.006 \\ 2,734(9.3 \%) & 2,183(9.4 \%) & 991(8.9 \%) & 0.21\end{array}$

Categorical variables are quoted as the $\mathrm{n}(\%)$, and continuous variables are quoted as the median [interquartile range (IQR)) or in quintiles OS, organized screening; OpS, opportunistic screening; FOBT, faecal occult blood test ; Data extraction in January 2016. Invitation sent during November 2010 and October 2012.

a. p-test from a chi-squared test; $b$. Number of women participating in at least one OS programme (including the OS in the study period); c. number of women invited 
to the OS in the study period; $d$. Number of areas for which information was available $=525$; e. Number of areas for which information was available = 505 
Table 4. Multivariable multinomial logistic regression of factors associated with partial participation (P1 and P2) and non-participation (NP) in the three cancer screening programmes, with full participation (FP) as the reference category $(n=11,750)(2010-2015)$

\begin{tabular}{|c|c|c|c|c|c|c|}
\hline \multirow[b]{3}{*}{ Fixed effects } & \multicolumn{2}{|c|}{ Non-participation } & \multicolumn{2}{|c|}{$\begin{array}{l}\text { Participation in } 1 \text { screening } \\
\text { programme }\end{array}$} & \multicolumn{2}{|c|}{$\begin{array}{c}\text { Participation in } 2 \text { screening } \\
\text { programmes }\end{array}$} \\
\hline & \multicolumn{2}{|c|}{ (NP) $\quad n=33,211^{a}$} & \multicolumn{2}{|c|}{ (P1) $n=30,793^{b}$} & \multicolumn{2}{|c|}{$(\mathrm{P} 2) \quad \mathrm{n}=24,506^{\mathrm{c}}$} \\
\hline & aOR $[95 \% \mathrm{Cl}]$ & $p$ value $^{d}$ & aOR [95\%Cl] & $p$ value ${ }^{d}$ & aOR [95\%Cl] & $p$ value $^{d}$ \\
\hline \multicolumn{7}{|l|}{ Level 1: individual } \\
\hline \multicolumn{7}{|l|}{ Age at the time of the initial invitation (years) } \\
\hline $50-54$ & Ref & $<0.001$ & Ref & 0.045 & Ref & $<0.001$ \\
\hline $55-59$ & 0.94 [0.89-0.99] & $<0.001^{*}$ & $0.93[0.89-0.99]$ & $<0.001^{*}$ & $0.90[0.86-0.95]$ & $<0.001^{*}$ \\
\hline $60-64$ & $0.90[0.85-0.95]$ & & $0.96[0.91-1.02]$ & & $0.91[0.86-0.96]$ & \\
\hline \multicolumn{7}{|l|}{ Statutory healthcare insurance scheme } \\
\hline Salaried workers & Ref & $<0.001$ & Ref & $<0.001$ & Ref & $<0.001$ \\
\hline Civil servants & $1.02[0.96-1.09]$ & & $1.12[1.04-1.20]$ & & $1.05[0.98-1.12]$ & \\
\hline Agricultural occupations & $2.74[1.78-4.21]$ & & $3.35[2.17-5.18]$ & & $1.54[0.98-2.44]$ & \\
\hline Self-employed workers & $3.76[3.23-4.38]$ & & $2.77[2.37-3.23]$ & & $1.55[1.32-1.82]$ & \\
\hline Large companies & $1.38[1.24-1.53]$ & & $1.50[1.34-1.67]$ & & 1.24 [1.11-1.39] & \\
\hline \multicolumn{7}{|l|}{ Previous mammography status ${ }^{\mathrm{e}}$} \\
\hline At least 1 normal result in an OS programme & --- & & Ref & $<0.001$ & Ref & $<0.001$ \\
\hline At least 1 abnormal in OS (false-positive findings) & & & $1.50[1.36-1.67]$ & & $1.18[1.07-1.31]$ & \\
\hline Previous mammography in OpS programmes only & & & $2.06[1.86-2.28]$ & & $1.81[1.64-1.99]$ & \\
\hline No previous mammography (OS or OpS) & & & $5.82[5.52-6.13]$ & & $1.86[1.76-1.96]$ & \\
\hline \multicolumn{7}{|l|}{ Level 2: Residence (area) } \\
\hline \multicolumn{7}{|l|}{ European Deprivation Index } \\
\hline Quintile 1 (least deprived) & Ref & $<0.001$ & Ref & 0.020 & Ref & 0.090 \\
\hline Quintile 2 & $1.25[1.14-1.36]$ & $<0.001^{*}$ & $1.12[1.03-1.21]$ & $0.030^{*}$ & $1.11[1.03-1.19]$ & $0.432 *$ \\
\hline Quintile 3 & $1.27[1.17-1.39]$ & & $1.07[0.99-1.16]$ & & $1.05[0.98-1.14]$ & \\
\hline Quintile 4 & $1.47[1.35-1.61]$ & & $1.06[0.98-1.15]$ & & $1.04[0.96-1.12]$ & \\
\hline Quintile 5 [most deprived) & $1.74[1.59-1.90]$ & & $1.14[1.05-1.24]$ & & $1.07[0.99-1.15]$ & \\
\hline Local radiologist in area & $0.94[0.85-1.02]$ & 0.144 & -- & & -- & \\
\hline \multicolumn{7}{|l|}{$\underline{\text { Random effects }}$} \\
\hline Level 2 variance (standard error) & $0.04[0.006]$ & & $0.02[0.006]$ & & $0.01[0.006]$ & \\
\hline likelihood ratio test $\chi^{2}(p)$ & $<0.001$ & & $<0.001$ & & 0.008 & \\
\hline Intraclass correlation coefficient (\%) & $1.11 \%^{\mathrm{f}}$ & & $0.6 \%^{\mathrm{g}}$ & & $0.31 \%^{h}$ & \\
\hline
\end{tabular}




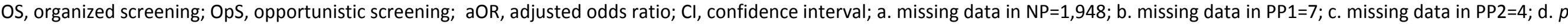

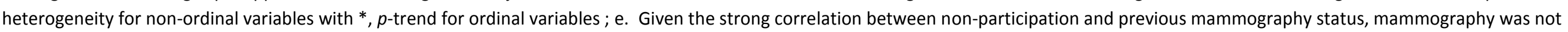

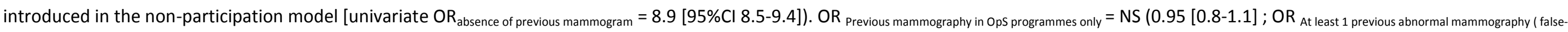
positive findings) in os $=1.4$ [1.2-1.5]. f, g, h: ICC in empty models: 2.1\%, 1\%, and 0.4\% ; Data extraction in January 2016. Invitation sent during November 2010 and October 2012.

Figure 1: Flow chart (2010-2015) 